http://dx.doi.org/10.22197/rbdpp.v1i1.11

\title{
O PRINCÍPIO DA PROPORCIONALIDADE COMO FERRAMENTA EFICAZ PARA A AFERIÇÃO DA ILEGITIMIDADE DA INDEVIDA RESTRIÇÃO A DIREITOS FUNDAMENTAIS, NO ÂMBITO DO PROCESSO PENAL
}

Marcelo Caetano Guazzelli Peruchin ${ }^{1}$

\begin{abstract}
RESUMO
O presente artigo busca lançar aportes doutrinários do direito constitucional aplicáveis ao processo penal no Estado Constitucional de Direito. Após uma breve introdução, são trabalhados subsídios teóricos com o objetivo de enaltecer a importância da proteção dos direitos fundamentais da pessoa, e, com isto, efetivar a legitimidade da intervenção estatal (a qual se dá, inclusive, por meio do processo penal na esfera das liberdades e dos direitos individuais), a partir da apreciação do princípio da proporcionalidade. Por fim, são abordados aspectos de diferenciação entre princípio da proporcionalidade proveniente da doutrina alemã e a razoabilidade trabalhada pelos Estados Unidos e Inglaterra.
\end{abstract}

PALAVRAS-CHAVE: Direitos fundamentais; Princípio da proporcionalidade; processo penal.

\section{ABSTRACT}

This essay seeks to expose doctrinal contributions applicable to criminal proceedings in the Constitutional rule of law. After an brief introduction, theorists aspects will be analyzed with the purpose to enhance the importance of individual fundamental rights protection. Moreover, the objective is to emphasyze the State's legitimacy of intervention (which is

\footnotetext{
1 Pós-doutor em Democracia e Direitos Humanos pela Universidade de Coimbra (2014). Doutor em Direito pela PUCRS (2012); Mestre em Ciências Criminais pela PUCRS (2000). Professor das disciplinas de Direito Penal, Processo Penal e Prática Jurídica na Faculdade de Direito da PUCRS. Investigador internacional do ICEPS (International Center of Economic Penal Studies). Advogado criminal.
} 
even done through the criminal process within the aspects of individual freedoms and rights), taking the proportionality principle as a starting point. Finnaly, aspects of differentiation betwen the principle of proportionality from the German doctrine and principle of razoability from the United States and England doctrine.

KEYWORDS: Fundamental rights; proportionality principle; criminal process.

O denominado princípio da proporcionalidade adquiriu grande relevância no âmbito do direito penal, vinculado às penas, visível preocupação exposta na obra Dos delitos e da penas, de Cesare de Beccaria, em 1764.

Luciano Feldens ${ }^{2}$ aponta como origem do princípio da proporcionalidade a Carta Magna de 1215, bem como relembra que no art. 8ํㅡㄹ da Declaração de Direitos do Homem e do Cidadão de 1789 constou que a lei não deve estabelecer outras penas que não as estrita e evidentemente necessárias. No campo do Direito Administrativo foi consagrado como uma evolução do princípio da legalidade, sendo que a sua sedimentação e migração para o Direito Constitucional se deu a partir da formação dos Estados modernos, em especial pelos movimentos de proteção dos direitos humanos, ocorridos na Europa Continental e na América no século XVIII. ${ }^{3}$

2 FELDENS, Luciano. Direitos fundamentais e direito penal. Porto Alegre: Livraria do Advogado, 2008. p. 81.

3 BARROS, Suzana de Toledo. O princípio da proporcionalidade e o controle de constitucionalidade das leis restritivas de direitos fundamentais. 2. ed. Brasília: Brasília Jurídica, 2000. p. 36-37. No que diz respeito à história do princípio da proporcionalidade ou da razoabilidade, merece destaque a contribuição de Fábio de Oliveira. Esse autor sustenta que a sua origem estaria em Aristóteles (quando já apregoava que o proporcional é o meio-termo, e o justo é o proporcional), sendo que no sistema da common law teve sua raiz na Magna Carta inglesa de 1215. Todavia, adverte que o princípio ganhou diferentes contornos entre a common law americana e inglesa, pois na primeira sempre foi marcante a supremacia da Constituição segundo declarada pelos juízes e tribunais, enquanto, para os ingleses, teve preponderância a vontade do legislativo por meio das leis que são fruto da vontade da maioria parlamentar. Na Europa ocidental, com o nome de proporcionalidade, a ideia do princípio surgiu ligada à teoria do desvio de poder, por obra do Conselho de Estado da França, na esfera administrativa. A partir daí, o critério da proporcionalidade chega para ser bem recebido em outros países, de acordo com as peculiaridades de cada um, tendo tido acolhida e desenvolvimento na Áustria, Itália, Espanha, Portugal e na Alemanha. A Alemanha ocidental, e. g., desempenhou papel de destaque na constitucionalização do princípio, tanto por meio da jurisprudência do Tribunal Constitucional, quanto da forte produção doutrinária, com base na Lei Fundamental de 23 de maio de 1949, a qual reconheceu normativamente o paradigma da proporcionalidade. O princípio da proporcionalidade ganhou emprego na aferição da discricionariedade legislativa com fulcro na teoria que o vincula diretamente aos direitos fundamentais, passando a ser considerado um autêntico direito fundamental. Assim, na Alemanha, o princípio da proporcionalidade recebe sede constitucional na previsão do Estado de direito (art. 20, 1 e 3; art. 28, 1, entre outros, da LF) como resultante da proteção ou execução dos direitos fundamentais (art. $2^{\circ}$, da LF, e. g.). OLIVEIRA, Fábio de. Por uma teoria dos princípios. O princípio constitucional da razoabilidade. 2. ed. Rio de Janeiro: Lumen Juris, 2007. p. 81-88. 
Para alguns autores, proporcionalidade e razoabilidade são expressões sinônimas; para outros, são conceitos distintos. ${ }^{4}$ Ingo Sarlet ${ }^{5}$ adverte que proporcionalidade e razoabilidade, a despeito de terem pontos comuns, não podem ser equiparados conceitualmente, pois a estrutura metodológica de aplicação da proporcionalidade em três níveis (adequação, necessidade e proporcionalidade em sentido estrito), tal como desenvolvida na Alemanha e amplamente recepcionada, não se confunde com o raciocínio utilizado quando da aplicação da razoabilidade.

Propugna-se a utilização do princípio da proporcionalidade como critério de interpretação constitucional, ${ }^{6}$ e, por força de seu manejo, viabilizar a proteção dos direitos fundamentais, também no universo do processo penal.

Foi na Alemanha, a propósito, que o princípio da proporcionalidade ganhou terreno para se desenvolver, partindo do Direito Administrativo para o Direito Constitucional, ${ }^{7}$ sendo construído a partir de inúmeras decisões judiciais que reco-

4 Em caráter de esclarecimento, a propósito, frisa-se que é adotado o entendimento de que as expressões proporcionalidade e razoabilidade são sinônimas para a identificação do princípio em comento, como o fazem MENDES, Gilmar Ferreira. Direitos fundamentais e controle de constitucionalidade: estudos de Direito Constitucional. 2. ed. São Paulo: Celso Bastos (Instituto Brasileiro de Direito Constitucional), 1999. p. 42 ss.; BASTOS, Celso Ribeiro. Hermenêutica e interpretação constitucional. São Paulo: Celso Bastos (Instituto Brasileiro de Direito Constitucional), 1997. p. 175 ss.; MENDES, Gilmar Ferreira; COELHO, Inocêncio Mártires; BRANCO, Paulo Gustavo Gonet. Curso de direito constitucional. 4. ed. São Paulo: Saraiva, 2009. p. 142. Todavia, há autores que defendem que tais expressões são distintas conceitualmente, dentre eles GUERRA FILHO, Willis Santiago. Processo constitucional e direitos fundamentais. 2. ed. São Paulo: Celso Bastos (Instituto Brasileiro de Direito Constitucional), 2001. p. 69; ÁVILA, Humberto. Teoria dos princípios. Da definição à aplicação dos princípios jurídicos. 12. ed. São Paulo: Malheiros, 2011. p. 101-103, 121; OLIVEIRA, Fábio de. Por uma teoria dos princípios. O princípio constitucional da razoabilidade. 2. ed. Rio de Janeiro: Lumen Juris, 2007. p. 91 ss. Este último autor, a título de ilustração, apregoa quanto à distinção: "É possível distinguir razoabilidade de proporcionalidade. [...] A razoabilidade abarca a proporcionalidade, mas nela não se esgota, porque tem um espectro normativo para além da relação entre motivo, meio e fim. Dito de outra maneira: a razoabilidade não se atém apenas ao controle da validade dos atos estatais (sejam ou não restritivos de direitos fundamentais)". Ibidem, p. 97. Igualmente entende que há distinção conceitual: STEINMETZ, Wilson Antônio. Colisão de direitos fundamentais e princípio da proporcionalidade. Porto Alegre: Livraria do Advogado, 2001. p. 148.

5 SARLET, Ingo Wolfgang; MARINONI, Luiz Guilherme; MITIDIERO, Daniel. Curso de direito constitucional. São Paulo: Revista dos Tribunais, 2012. p. 213-214. Também em ÁVILA, Humberto. Teoria dos princípios. Da definição à aplicação dos princípios jurídicos. 12. ed. São Paulo: Malheiros, 2011. p. 159 ss.

6 Nesse sentido, a lição de Ingo Sarlet. SARLET; MARINONI; MITIDIERO. Op. cit., p. 212. Com uma abordagem acerca da aplicação hermenêutica do princípio da proporcionalidade em casos concretos e daí a densificação de seu conteúdo e expansão de sua abrangência, vide MENDES; COELHO; BRANCO. Op. cit., p. 143-144.

7 Ingo Sarlet indica o direito administrativo prussiano como tendo sido a origem do princípio da proporcionalidade, aduzindo que tem em sua essência a noção de controle dos atos do Poder Público, com a característica de coibir excessos de intervenção na esfera dos direitos dos cidadãos; tendo evoluído, todavia, para servir de critério de aferição também da legitimidade constitucional dos atos legislativos e mesmo das decisões judiciais. Esta evolução, combinando as noções de proporcionalidade e de razoabilidade, acabou por habilitar as pessoas a contestar determinados atos do Estado ofensivos ou restritivos de seus direitos fundamentais. SARLET, Ingo Wolfgang; MARINONI, Luiz Guilherme; MITIDIERO, Daniel. Curso de Direito constitucional. São 
nheceram que o legislador não se deve exceder na restrição aos direitos fundamentais, a título de exemplificação.

A Constituição alemã de 1949, no firme afã de tutelar os direitos fundamentais, pondo-os a salvo do arbítrio legalizado, assentou, em seu art. 1ํㅡㅇ o caráter vinculante destes direitos para os poderes do Estado, e, em seu art. 19, consagrou o princípio da proteção do núcleo essencial dos direitos fundamentais, ao estatuir que qualquer restrição a eles há de se dar por lei necessária, geral e que não afete seu conteúdo essencial, garantindo ampla possibilidade de tutela jurisdicional em caso de virem a sofrer violações. O Tribunal Constitucional Alemão, assimilando tal preocupação estampada na Constituição alemã, erigiu a proteção e controle às restrições legislativas aos direitos fundamentais no que alude aos três aspectos: necessidade, adequação e proporcionalidade da medida restritiva em exame (proporcionalidade em sentido estrito) ${ }^{8}$

Segundo Gilmar Ferreira Mendes, ${ }^{9}$

"no direito constitucional alemão, outorga-se ao princípio da proporcionalidade ou ao princípio da proibição de excesso qualidade de norma constitucional não escrita, derivada do Estado de Direito. Cuida-se, fundamentalmente, de aferir a compatibilidade entre meios e fins, de molde a evitar restrições desnecessárias ou abusivas contra os direitos fundamentais".

Luís Roberto Barroso ${ }^{10}$ refere que o princípio da razoabilidade teve sua origem e desenvolvimento ligados à garantia do devido processo legal, originário, este, da Magna Carta de 1215. Por isso, relevante a lembrança de que o princípio do devido processo legal foi marcado pela fase inicial processual e por uma segunda fase material, sendo que esta se tornou importante instrumento de defesa dos direitos individuais, permitindo o controle do arbítrio do Legislativo e da discricionariedade governamental. A fase processual representava uma garantia voltada à regularidade do processo penal, depois estendida ao processo civil e ao processo administrativo. Seu campo de incidência recaía principalmente no direito ao contraditório e à ampla defesa, incluindo o direito a ter um

Paulo: Revista dos Tribunais, 2012. p. 212. Luciano Feldens, por sua vez, aponta a decisão do Tribunal Constitucional Federal da Alemanha [BVerfGE 19, 342 (348)], de 1965, como sendo a pioneira na aceitação da estatura jurídico-constitucional do princípio da proporcionalidade. FELDENS, Luciano. Direitos fundamentais e direito penal. Porto Alegre: Livraria do Advogado, 2008. p. 81.

8 BARROS, Suzana de Toledo. O princípio da proporcionalidade e o controle de constitucionalidade das leis restritivas de direitos fundamentais. 2. ed. Brasília: Brasília Jurídica, 2000. p. 46. Vide, igualmente, sobre a temática: FELDENS. Op. cit., p. 82-90. Também em MENDES, Gilmar Ferreira; COELHO, Inocêncio Mártires; BRANCO, Paulo Gustavo Gonet. Curso de direito constitucional. 4. ed. São Paulo: Saraiva, 2009. p. 143.

9 MENDES, Gilmar Ferreira. Controle de constitucionalidade: aspectos jurídicos e políticos. São Paulo: Saraiva, 1990. p. 43.

10 BARROSO, Luís Roberto. Interpretação e aplicação da constituição. 6. ed. São Paulo: Saraiva, 2006. p. 219220. Vide, sobre o tema, igualmente, OLIVEIRA, Fábio de. Por uma teoria dos princípios. O princípio constitucional da razoabilidade. 2. ed. Rio de Janeiro: Lumen Juris, 2007. p. 88. 
advogado e o acesso à justiça para as pessoas. Por meio da fase substancial ou material do princípio do due process of law, abriu-se espaço para o controle do mérito dos atos do Poder Público, com a redefinição da noção de discricionariedade. Desse modo, a cláusula do devido processo legal permite a verificação da compatibilidade entre o meio empregado pelo legislador e os fins visados, bem como a aferição da legitimidade dos fins.

Conforme ressaltou Suzana de Toledo Barros, ${ }^{11}$ o controle de razoabilidade das leis mediante um parâmetro técnico dado pelo princípio da proporcionalidade representou uma virada científica de grande repercussão junto aos países europeus que adotam controle jurisdicional de constitucionalidade, como Portugal, Espanha, Itália e Áustria, irradiando-se mais recentemente ao Brasil, por intermédio da forte influência dos constitucionalistas portugueses na doutrina e jurisprudência nacionais.

A título de informação, na Itália, o controle da constitucionalidade das leis foi introduzido, de forma explícita, em 1948, porém, somente em 1953 foi regulamentado. Segundo Suzana de Toledo Barros, ${ }^{12}$ a proteção dos direitos fundamentais na justiça italiana processa-se na via ordinária e o controle de constitucionalidade das leis que devam ser aplicadas a um determinado caso é alcançado por um procedimento incidental, produzido por uma ordenanza de reenvio, o que significa que o juiz a quo ordena a remessa dos autos ao Tribunal Constitucional para a solução da questão prejudicial, ao mesmo tempo em que suspende o curso do processo. O impedimento do Tribunal Constitucional de examinar o poder discricionário do legislador foi desde logo atenuada pela recepção da doutrina constitucional alemã pelo Convênio Europeu para a Proteção dos Direitos Humanos do qual a Itália é signatária.

Como se sabe, a jurisprudência do Tribunal Constitucional Alemão foi de grande significado no desenvolvimento do princípio da proporcionalidade. Em julgado de 1971, restou definido que

“[...] o meio empregado pelo legislador deve ser adequado e exigível, para que seja atingido o fim almejado. O meio é adequado quando, com o seu auxílio, se pode promover o resultado desejado; ele é exigível quando o legislador não poderia ter escolhido outro igualmente eficaz, mas que seria um meio não prejudicial ou portadora de uma limitação menos perceptível a direito fundamental". ${ }^{13}$

Comenta Luís Roberto Barroso ${ }^{14}$ que essa decisão indicou a presença de outro requisito qualificador da razoabilidade-proporcionalidade, que é o da exigibilidade ou necessidade, conhecido como princípio da menor ingerência possível, também conhecida pela expressão proibição de excesso.

11 BARROS, Suzana de Toledo. O princípio da proporcionalidade e o controle de constitucionalidade das leis restritivas de direitos fundamentais. 2. ed. Brasília: Brasília Jurídica, 2000. p. 48.

12 Ibidem, p. 49.

13 BARROSO, Luís Roberto. Interpretação e aplicação da Constituição. 6. ed. São Paulo: Saraiva, 2006. p. 227.

14 Ibidem, p. 227-228. A decisão é mencionada pelo autor: BVerfGE, 30, 292 (316). 
Na Espanha, por sua vez, a recepção do Direito Constitucional alemão é mais recente, em face da longa ditadura de Franco (1936 a 1975). O princípio da proporcionalidade foi construído e positivado, durante a ditadura de Franco, no Direito Administrativo espanhol, como limitação à intervenção administrativa sobre as esferas jurídico-privadas. Quanto à aplicação do princípio da proporcionalidade no controle de constitucionalidade, e. g., viabilizou-se com a promulgação da Constituição de 1978, a qual previu um sólido sistema de proteção aos direitos fundamentais, deixando expresso o seu caráter vinculante e a necessidade que a respectiva legislação regulamentadora respeite o seu conteúdo essencial. Como leciona Suzana de Toledo Barros, ${ }^{15}$ a falta de positivação do princípio da proporcionalidade na Espanha não foi empecilho para o seu reconhecimento de parte do Poder Judiciário no controle de eventuais excessos do legislador, dada a forte influência doutrinária alemã naquele país, bem como em face da incidência do Convênio Europeu de Direitos Humanos, considerado como norma integrativa da Constituição, sendo que os arestos do Tribunal Europeu de Direitos Humanos são, em grande medida, assimilados pela jurisprudência daquele país.

Modernamente, entende-se que o Poder Judiciário, ao realizar a necessária ponderação entre os direitos fundamentais em conflito, deve proceder caso a caso, no propósito de valorar em que medida uma liberdade deve ceder passo à outra. Nesse contexto, deve estar sempre presente, para o órgão julgador, o requisito da proporcionalidade. ${ }^{16}$

Como visto, um dos enfoques estruturais do Estado Constitucional de Direito é a limitação do poder estatal, sendo que as intervenções no âmbito dos direitos fundamentais são com ele compatíveis quando ocorrerem de maneira moderada e não violarem o "núcleo essencial" dos direitos restringidos, de modo injustificado. Esse é, na visão de Cláudio Pereira de Souza Neto, ${ }^{17}$ o conteúdo substantivo do princípio da proporcionalidade ou da razoabilidade, segundo o qual somente as restrições "adequadas", "necessárias", e "justificadas" são compatíveis com a Constituição.

Comunga-se com a doutrina de Cláudio Pereira de Souza Neto, ${ }^{18}$ no sentido de que tal princípio possui natureza (além de formal, também) material. Portanto, integra e compõe a essência do Estado Constitucional e é parâmetro para a "aferição da própria

15 BARROS, Suzana de Toledo. O princípio da proporcionalidade e o controle de constitucionalidade das leis restritivas de direitos fundamentais. 2. ed. Brasília: Brasília Jurídica, 2000. p. 52.

16 CARVALHO, Luis Gustavo Grandinetti Castanho de. Liberdade de informação e o direito difuso à informação verdadeira. Rio de Janeiro: Renovar, 1994. p. 87. Também em MENDES, Gilmar Ferreira; COELHO, Inocêncio Mártires; BRANCO, Paulo Gustavo Gonet. Curso de direito constitucional. 4. ed. São Paulo: Saraiva, 2009. p. 143-144.

17 SOUZA NETO, Cláudio Pereira de. Teoria constitucional e democracia deliberativa. Op. cit. p. 29-30. Também neste sentido, ver MENDES; COELHO; BRANCO. Op. cit., p. 143.

18 SOUZA NETO, Cláudio Pereira de. Teoria constitucional e democracia deliberativa. Um estudo sobre o papel do direito na garantia das condições para a cooperação na deliberação democrática. Rio de Janeiro: Renovar, 2006. p. 30-31. Paulo Bonavides chega a elevar o princípio da proporcionalidade ao patamar de um princípio geral de direito. BONAVIDES, Paulo. Curso de direito constitucional. 9. ed. São Paulo: Malheiros, 2000. p. 364. 
constitucionalidade material dos atos estatais", incluindo neles, por evidente, as decisões judiciais proferidas no processo criminal.

Luciano Feldens ${ }^{19}$ indica que na doutrina e jurisprudência alemãs, a proporcionalidade é tida como princípio inerente ao Estado de Direito, consubstanciando-se em uma das garantias básicas que devem ser observadas em todo caso onde estejam periclitando direitos e liberdades fundamentais, qualificando-se, deste modo, como máxima constitucional. No Brasil, recorda o autor, o Supremo Tribunal Federal inclina-se por conceber a proporcionalidade como postulado constitucional que encontra a sua raiz material no princípio do devido processo legal (art. 5ㅜ, LIV, da CF), em sua perspectiva substancial.

Como muito bem asseverou Gilmar Mendes, ${ }^{20}$

“[...] o princípio da proporcionalidade ou da razoabilidade consubstancia uma pauta de natureza axiológica que emana diretamente das ideias de justiça, equidade, bom senso, prudência, moderação, justa medida, proibição de excesso, direito justo e valores afins; precede e condiciona a positivação jurídica, inclusive a de nível constitucional; e, ainda, enquanto princípio geral do direito, serve de regra de interpretação para todo o ordenamento jurídico".

É possível visualizar o princípio da proporcionalidade, pois, a partir de um dúplice enfoque, tanto como um critério de controle da legitimidade constitucional de medidas restritivas de direitos fundamentais, bem como para o controle da omissão ou atuação insuficiente do Estado no cumprimento de seus deveres de proteção. Da noção de proteção e defesa, o princípio também avançou para a correção de omissões relevantes do Estado, correspondendo tanto à função de proibição de excesso quanto da de proibição da proteção suficiente, ambas com inegável relevância jurídico-social. ${ }^{21}$

Em realidade, não se pretendeu, aqui, nos lindes desse artigo acadêmico, esgotar a análise sobre o princípio da proporcionalidade, mas, tão-somente, reconhecer nele uma importante ferramenta para a identificação da ilegitimidade de toda a restrição abusiva ou indevida na esfera dos direitos fundamentais e das garantias da pessoa, de modo desequilibrado, imoderado, desnecessário, desmedido. Muito especialmente no processo penal, palco onde desfilam a pretensão acusatória estatal (de um lado) e a pretensão de resistência do acusado e de sua defesa técnica.

Os direitos fundamentais, quanto à forma de seu exercício, podem entrar em conflito. Portanto, cabe ao Poder Judiciário não somente a efetivação dos direitos fundamentais, bem como a solução do conflito entre eles, muitas vezes optando por uns em detrimento de outros, diante do caso concreto. A dirimência desse conflito se constitui em um dos modernos papéis exercidos pelo Judiciário na sociedade pós-moderna.

19 FELDENS, Luciano. Direitos fundamentais e direito penal. Porto Alegre: Livraria do Advogado, 2008. p. 81-82.

20 MENDES, Gilmar Ferreira; COELHO, Inocêncio Mártires; BRANCO, Paulo Gustavo Gonet. Curso de direito constitucional. 4. ed. São Paulo: Saraiva, 2009. p. 143.

21 Vide em SARLET, Ingo Wolfgang; MARINONI, Luiz Guilherme; MITIDIERO, Daniel. Curso de direito constitucional. São Paulo: Revista dos Tribunais, 2012. p. 213-214. 
Basta que se coloquem tais direitos lado a lado, para se concluir que pode haver conflito entre ambos, de modo que tais direitos não poderão ser compreendidos como absolutos, nem será suficiente delimitar seu âmbito de proteção. Trata-se de normas de direitos fundamentais diferentes, atribuídos a titulares diversos, que podem colidir na aplicação. $^{22}$

Os conflitos se explicam, em boa medida, pelo reflexo, no texto constitucional, de diferentes pretensões, que necessitam conviver e se harmonizar em uma sociedade plural. A coexistência dessas pretensões acarreta, portanto, colisões entre diferentes comandos constitucionais, embora imbuídos de igual hierarquia. ${ }^{23}$ Diante disso, importante a compreensão dos limites.

A noção de limites dos direitos fundamentais não pode soar estranha, nem se restringe às hipóteses de restrições expressamente previstas e delimitadas no texto constitucional. Como sustenta Luis Gustavo Grandinetti de Carvalho, ${ }^{24}$ quando a Constituição habilita o legislador a limitar um direito fundamental, deve-se entender que não o faz somente para proteger o bem a que alude, mas também para impor outras limitações, desde que justificadas pela proteção dos demais direitos fundamentais e dos bens constitucionalmente reconhecidos.

O risco dessa concepção, no entanto, é o de se admitir uma "pura ponderação entre valores ou princípios opostos, baseada em critérios verdadeiramente decisionistas". ${ }^{25}$ Que a solução de conflitos entre direitos fundamentais depende de uma ponderação entre os interesses em choque parece ser consenso. Há que se estabelecer, porém, um esquema metodológico que permita evitar atribuição arbitrária de maior ou menor valor a um dos direitos em tensão.

A superação dessa insegurança se pode obter através de uma jurisprudência constitucional (e criminal) orientada racionalmente pela máxima da proporcionalidade. ${ }^{26}$

Na lição de J. J. Gomes Canotilho, ${ }^{27}$ entre o fim da autorização constitucional para uma emanação de leis restritivas e o exercício do poder discricionário por parte do legislador ao realizar este fim deve buscar uma indelével conexão material de meios e fins.

22 ALEXY, Robert. Colisão de direitos fundamentais e realização de direitos no estado de direito democrático. Revista de Direito Administrativo. Rio de Janeiro, v. 2, nº 17, p. 70, 1999.

23 BARCELLOS, Ana Paula de. Neoconstitucionalismo, direitos fundamentais e controle das políticas públicas. Revista Diálogo Jurídico. Salvador, nº 15, p. 6, jan./mar. 2007.

24 CARVALHO, Luis Gustavo Grandinetti Castanho de. Liberdade de informação e o direito difuso à informação verdadeira. Rio de Janeiro: Renovar, 1994. p. 26.

25 BORNHOLDT, Rodrigo Meyer. Métodos para resolução do conflito entre direitos fundamentais. São Paulo: Revista dos Tribunais, 2005. p. 176.

26 ALEXY, Robert. Teoria dos direitos fundamentais. São Paulo: Malheiros, 2008. p. 325.

27 CANOTILHO, J. J. Gomes. Direito constitucional. 5. ed. Coimbra: Almedina, 1991. p. 488. 
O chamado princípio da proporcionalidade compreende três subprincípios ou momentos metodológicos: adequação, necessidade e proporcionalidade em sentido estrito. ${ }^{28}$

Inicialmente, verificando o pressuposto da adequação, deve o intérprete aferir se a medida questionada representa o meio certo para realização de um fim. Examina-se a conformidade ou validade do fim, verificando-se se a medida é suscetível de atingi-lo. ${ }^{29} \mathrm{O}$ pressuposto da adequação exige, pois, que as medidas interventivas adotadas mostrem-se aptas a atingir os objetivos pretendidos. ${ }^{30}$

O segundo passo metodológico ou pressuposto a examinar, de acordo com o princípio da proporcionalidade, é o da necessidade, amparado na inexistência de meio mais ameno, menos interventor. ${ }^{31}$ De acordo com a exigência da necessidade, de todas as medidas que igualmente servem à obtenção de um fim, cumpre eleger aquela menos nociva aos interesses do cidadão. ${ }^{32}$

Finalmente, há que se perquirir sobre a proporcionalidade em sentido estrito, também chamada razoabilidade. Mesmo uma medida adequada e necessária poderá ser desproporcional..$^{33}$ Por razoável deve-se entender tudo aquilo que seja conforme a razão, supondo equilíbrio, moderação e harmonia; ${ }^{34}$ o que não seja arbitrário ou caprichoso; o que corresponda ao senso comum; ${ }^{35}$ aos valores vigentes em dado momento ou lugar. ${ }^{36}$

A proporcionalidade em sentido estrito traduz-se na justa medida. ${ }^{37}$ Um juízo definitivo sobre a proporcionalidade ou razoabilidade da medida há de resultar da rigorosa

28 Esses três subprincípios, enquanto classificação, derivados do princípio da proporcionalidade, encontram acolhida doutrinária, como se observa, e. g., na obra de SARLET, Ingo Wolfgang; MARINONI, Luiz Guilherme; MITIDIERO, Daniel. Curso de direito constitucional. São Paulo: Revista dos Tribunais, 2012. p. 213; OLIVEIRA, Fábio de. Por uma teoria dos princípios. O princípio constitucional da razoabilidade. 2. ed. Rio de Janeiro: Lumen Juris, 2007. p. 97 ss. Vide, igualmente, MENDES, Gilmar Ferreira; COELHO, Inocêncio Mártires; BRANCO, Paulo Gustavo Gonet. Curso de direito constitucional. 4. ed. São Paulo: Saraiva, 2009. p. 143.

29 BONAVIDES, Paulo. Curso de direito constitucional. 16. ed. São Paulo: Malheiros, 2005. p. 396-397. Vide, igualmente, FELDENS, Luciano. Direitos fundamentais e direito penal. Porto Alegre: Livraria do Advogado, 2008. p. 82.

30 MENDES, Gilmar Ferreira. Direitos fundamentais e controle de constitucionalidade: estudos de Direito Constitucional. 2. ed. São Paulo: Celso Bastos (Instituto Brasileiro de Direito Constitucional), 1999. p. 43.

31 WEINGARTNER, Jayme. Honra, privacidade e liberdade de imprensa: uma pauta de justificação penal. Porto Alegre: Livraria do Advogado, 2002. p. 133. FELDENS, Luciano. Direitos fundamentais e direito penal. Porto Alegre: Livraria do Advogado, 2008. p. 82-83.

32 BONAVIDES, Paulo. Curso de direito constitucional. 16. ed. São Paulo: Malheiros, 2005. p. 397.

33 SARLET, Ingo Wolfgang. Constituição, proporcionalidade e direitos fundamentais: o direito penal entre proibição de excesso e de insuficiência. Boletim da Faculdade de Direito da Universidade de Coimbra, Coimbra, v. LXXXI (Separata), p. 365, 2005.

34 BIELSA, Rafael. Derecho administrativo. 6. ed. Buenos Aires: La Ley, 1964. p. 485.

35 QUINTANA, V. Linares. Reglas para la interpretación constitucional. Buenos Aires: Plus Ultra, 1987. p. 122.

36 BARACHO, José Alfredo de Oliveira. Processo e constituição: o devido processo legal. Belo Horizonte: UFMG, s.d. p. 90.

37 CANOTILHO, J. J. Gomes. Direito constitucional e teoria da constituição. 7. ed. Coimbra: Almedina, 2003. p. 457 . FELDENS. Op. cit., p. 85. 
ponderação entre o significado da intervenção para o atingido e os objetivos perseguidos. ${ }^{38}$ Exigir-se-á, pois, que o sacrifício imposto a um dos direitos fundamentais possa ser compreendido como medida ponderada, equilibrada, temperada pelo bom senso. ${ }^{39}$

A aplicação do princípio da proporcionalidade, assim, deve servir de critério prático para resolução de casos de colisão entre normas de natureza constitucional; de acordo com o princípio da proporcionalidade, que deve regular a ponderação entre interesses quando conflitarem, quanto maior for a intensidade da compressão dos direitos fundamentais em presença, tanto maior deverá ser o peso das razões de interesse público mobilizadas para a sua justificação. ${ }^{40}$

Com efeito, com enorme utilidade na presença de casos concretos, mediante indispensável ponderação entre o interesse público e o privado, norteada sempre pelo princípio da proporcionalidade em seus três diferentes momentos, sendo este princípio de inegável relevo no cenário do processo penal e nas decisões nele proferidas.

Nesse contexto, as decisões judiciais proferidas no processo penal devem guardar a observância possível do princípio da proporcionalidade, pois dessa forma estarão revestidas de legitimidade formal e material. Essa constatação ganha relevo sempre que a decisão judicial importar em restrição a direito fundamental do réu, e.g., a decisão que decreta medidas cautelares pessoais ou reais, dentre outras.

A atuação do Poder Judiciário deverá implicar na mínima restrição necessária aos direitos fundamentais e às garantias do demandado, com vistas à consecução do fim ao qual se propõe a decisão processual penal. Em outras palavras, a decisão judicial deverá colimar a máxima efetividade com a menor restrição possível aos direitos fundamentais e às garantias do acusado, e essa bússola é orientada pelo princípio da proporcionalidade, mesmo que a averiguação de tal medida dependa do exame do caso concreto e de suas circunstâncias.

Acaso a decisão judicial, proferida em sede de processo penal, importe em violação ou descumprimento do princípio da proporcionalidade (inegavelmente presente no arcabouço constitucional do Estado brasileiro), a consequência será a da sua invalidade, reflexo de magnitude no terreno das nulidades processuais. Ou seja, a violação ao princípio da proporcionalidade pode servir de fundamento (ou de ratio decidendi) para o decreto de invalidade da decisão exarada no seio de um processo penal, e que o tenha descumprido.

\footnotetext{
38 MENDES, Gilmar Ferreira. Direitos fundamentais e controle de constitucionalidade: estudos de direito constitucional. 2. ed. São Paulo: Celso Bastos (Instituto Brasileiro de Direito Constitucional), 1999. p. 44.

39 Assevera Willis Santiago Guerra Filho que uma medida é adequada se atinge o fim almejado, exigível, por causar o menor prejuízo possível e finalmente, proporcional em sentido estrito, se as vantagens que acarrete superarem as desvantagens. GUERRA FILHO, Willis Santiago. Ensaios de teoria constitucional. Fortaleza: Imprensa Universitária, 1989. p. 75.

40 MACHADO, Jónatas E. M. Liberdade de programação televisiva: notas sobre os seus limites constitucionais negativos. In: SARLET, Ingo Wolfgang (Org.). Direitos fundamentais, informática e comunicação. Porto Alegre: Livraria do Advogado, 2007. p. 139.
} 
Esse é um interesse caminho para que o princípio da proporcionalidade adquira força normativa, saindo do campo da abstração e encontrando vida e efetividade, o que resultará no fortalecimento da própria estrutura do Estado Constitucional de Direito e do processo penal democrático que lhe deve ser correspondente.

\section{Bibliografia}

ALEXY, Robert. Colisão de direitos fundamentais e realização de direitos no estado de direito democrático. Revista de Direito Administrativo, Rio de Janeiro, no 217, p. 67-79, jul./set. 1999.

. Teoria dos direitos fundamentais. São Paulo: Malheiros, 2008.

ÁVILA, Humberto. Teoria dos princípios. Da definição à aplicação dos princípios jurídicos. 12. ed. São Paulo: Malheiros, 2011.

BARACHO, José Alfredo de Oliveira. Processo e Constituição: o devido processo legal. Belo Horizonte: UFMG, s.d.

BARCELLOS, Ana Paula de. Neoconstitucionalismo, direitos fundamentais e controle das políticas públicas. Revista Diálogo Jurídico, Salvador, nº 15, p. 6, jan./mar. 2007.

BARROS, Suzana de Toledo. O princípio da proporcionalidade e o controle de constitucionalidade das leis restritivas de direitos fundamentais. 2. ed. Brasília: Brasília Jurídica, 2000.

BARROSO, Luís Roberto. Interpretação e aplicação da Constituição. 6. ed. São Paulo: Saraiva, 2006.

BASTOS, Celso Ribeiro. Hermenêutica e interpretação constitucional. São Paulo: Celso Bastos (Instituto Brasileiro de Direito Constitucional), 1997.

BIELSA, Rafael. Derecho administrativo. 6. ed. Buenos Aires: La Ley, 1964.

BONAVIDES, Paulo. Curso de direito constitucional. 16. ed. São Paulo: Malheiros, 2005.

. Curso de direito constitucional. 9. ed. São Paulo: Malheiros, 2000.

BORNHOLDT, Rodrigo Meyer. Métodos para resolução do conflito entre direitos fundamentais. São Paulo: Revista dos Tribunais, 2005.

CANOTILHO, J. J. Gomes. Direito constitucional. 5. ed. Coimbra: Almedina, 1991.

. Direito constitucional e teoria da Constituição. 7. ed. Coimbra: Almedina, 2003.

CARVALHO, Luis Gustavo Grandinetti Castanho de. Liberdade de informação e o direito difuso à informação verdadeira. Rio de Janeiro: Renovar, 1994.

FELDENS, Luciano. Direitos fundamentais e direito penal. Porto Alegre: Livraria do Advogado, 2008. 
GUERRA FILHO, Willis Santiago. Ensaios de teoria constitucional. Fortaleza: Imprensa Universitária, 1989.

. Processo constitucional e direitos fundamentais. 2. ed. São Paulo: Celso Bastos (Instituto Brasileiro de Direito Constitucional), 2001.

MACHADO, Jónatas E. M. Liberdade de programação televisiva: notas sobre os seus limites constitucionais negativos. In: SARLET, Ingo Wolfgang (Org.). Direitos fundamentais, informática e comunicação. Porto Alegre: Livraria do Advogado, 2007.

MENDES, Gilmar Ferreira. Controle de constitucionalidade: aspectos jurídicos e políticos. São Paulo: Saraiva, 1990.

. Direitos fundamentais e controle de constitucionalidade: estudos de direito constitucional. 2. ed. São Paulo: Celso Bastos (Instituto Brasileiro de Direito Constitucional), 1999.

; COELHO, Inocêncio Mártires; BRANCO, Paulo Gustavo Gonet. Curso de direito constitucional. 4. ed. São Paulo: Saraiva, 2009.

OLIVEIRA, Fábio de. Por uma teoria dos princípios. O princípio constitucional da razoabilidade. 2. ed. Rio de Janeiro: Lumen Juris, 2007.

QUINTANA, V. Linares. Reglas para la interpretación constitucional. Buenos Aires: Plus Ultra, 1987.

SARLET, Ingo Wolfgang; MARINONI, Luiz Guilherme; MITIDIERO, Daniel. Curso de direito constitucional. São Paulo: Revista dos Tribunais, 2012.

SOUZA NETO, Cláudio Pereira de. Teoria constitucional e democracia deliberativa. Um estudo sobre o papel do direito na garantia das condições para a cooperação na deliberação democrática. Rio de Janeiro: Renovar, 2006.

STEINMETZ, Wilson Antônio. Colisão de direitos fundamentais e princípio da proporcionalidade. Porto Alegre: Livraria do Advogado, 2001.

WEINGARTNER, Jayme. Honra, privacidade e liberdade de imprensa: uma pauta de justificação penal. Porto Alegre: Livraria do Advogado, 2002.

\section{Como citar este artigo:}

PERUCHIN, Marcelo Caetano Guazzelli. O princípio da proporcionalidade como ferramenta eficaz para a aferição da ilegitimidade da indevida restrição a direitos fundamentais, no âmbito do processo penal. Revista Brasileira de Direito Processual Penal, Porto Alegre, vol. 1, n. 1, p. 218-229, 2015. http://dx.doi.org/10.22197/ rbdpp.v1i1.11 